\title{
Delayed Implantation of a Peripheral Nerve Graft Reduces Motoneuron Survival but Does Not Affect Regeneration following Spinal Root Avulsion in Adult Rats
}

\author{
WUTIAN WU, HONG CHAI, JIANYI ZHANG, HUAIYU GU, \\ YUANYUN XIE, and LIHUA ZHOU
}

\begin{abstract}
Adult spinal motoneurons can regenerate their axons into a peripheral nerve (PN) graft following root avulsion injury if the graft is implanted immediately after the lesion is induced. The present study was designed to determine how avulsed motoneurons respond to a PN graft if implantation takes place a few days to a few weeks later. Survival, regeneration, and gene expression changes of injured motoneurons after delayed PN graft implantation were studied. The survival rates of spinal motoneurons were $78 \%, 65 \%, 57 \%$, or $53 \%$ if a PN graft was implanted immediately, 1, 2, or 3 weeks after root avulsion, respectively. Interestingly, most of the surviving motoneurons were able to regenerate their axons into the graft regardless of the delay. All regenerating motoneurons expressed p75, but not nNOS, while all motoneurons that failed to regenerate expressed nNOS, but not p75. p75 and nNOS may, therefore, be used as markers for success or failure to regenerate axons. In the group with immediate graft implantation, $85 \%$ of the surviving motoneurons extended axons into the PN graft, while in the groups in which implantation was delayed 1, 2, or 3 weeks, $84 \%, 82 \%$, and $83 \%$ of the surviving motoneurons, respectively, were found to have regenerated into the grafts. These findings indicate that avulsed spinal motoneurons retain the ability to regenerate for at least 3 weeks, and perhaps for as long as they survive. Therefore, the delayed implantation of a PN graft after root avulsion may provide a continued conducive environment to support regeneration.
\end{abstract}

Key words: nitric oxide synthase; p75; PN graft implantation; root avulsion; spinal motoneurons

\section{INTRODUCTION}

$\mathbf{I}$ N ADULT RATS, the majority of spinal motoneurons survive after axotomy of a peripheral nerve (PN) if at least $5 \mathrm{~mm}$ of PN remains ( $\mathrm{Gu}$ et al., 1997), but, however, most motoneurons degenerate if the axotomy is performed closer to the cell body. In the case of spinal root avulsion, which injures motoneuron axons close to the cell body, dramatic motoneuron death ensues in the affected spinal segment (Wu, 1993; Koliatsos et al., 1994; Novikov et al., 1995). This response to root avulsion may be due to the complete loss of trophic support from the PN component, since PN graft implantation immediately after avulsion can prevent such motoneuron loss (Wu et al., 1994a).

Adult rat spinal motoneurons express neuronal nitric

Department of Anatomy, Faculty of Medicine, The University of Hong Kong, Hong Kong, China. 
oxide synthase (nNOS) following root avulsion (Wu, 1993, 1996; Wu et al., 1994b). Expression of nNOS in injured motoneurons begins at 1 week and reaches a maximum 3-4 weeks postinjury. The peak level of mNOS seems to trigger motoneuron death, since significant cell loss in the avulsed segment of the spinal cord occurs starting at 4 weeks postinjury (Wu, 1993). It is interesting to note that implantation of a PN graft immediately after root avulsion not only enhances the survival of motoneurons but also inhibits the expression of nNOS in the injured motoneurons (Wu et al., 1994a; Wu, 1996). These findings suggest that avulsed motoneurons may obtain trophic support from the implanted PN graft before the expression of nNOS is initiated, which in turn prevents the death of injured motoneurons. However, it is not clear whether injured motoneurons can survive if graft implantation is delayed until nNOS is expressed in the injured motoneurons. The proportion of motoneurons that retain the ability to regenerate if implantation is delayed is also unknown.

In earlier studies of PN graft implantation performed immediately after root avulsion, we found that low-affinity nerve growth factor receptor (p75) is re-expressed in all regenerating motoneurons but not in nonregenerating ones (Wu et al., 1994a; Wu, 1996), but again the role of such re-expression is not clear.

The present study was designed to determine (1) whether motoneuron death due to root avulsion continues if PN graft implantation is delayed; (2) whether injured motoneurons can regenerate into a PN graft implanted when nNOS is expressed by these neurons; (3) whether expression of nNOS and p75 in injured motoneurons can be regulated by PN grafts implanted after a delay; and (4) how delayed PN graft implantation affects motoneuron regeneration.

\section{MATERIALS AND METHODS}

\section{Surgical Procedures}

All of the procedures used in this study were approved by the Committee on the Use of Live Animals for Teaching and Research of the Faculty of Medicine at the University of Hong Kong.

Adult male Sprague-Dawley rats (200-250 g) underwent root avulsion following the surgical procedure described previously (Wu, 1996). Briefly, animals were anesthetized by intramuscular injection of ketamine ( 80 $\mathrm{mg} / \mathrm{kg})$ and xylazine $(8 \mathrm{mg} / \mathrm{kg}$ ) and a dorsal laminectomy was carried out under aseptic conditions. The seventh cervical (C7) spinal roots (both dorsal and ventral) were identified and avulsed with microhemostat forceps. The avulsed roots and dorsal root ganglia were cut away from the peripheral nerve and examined under a dissecting microscope to confirm the success of the avulsion. One group of 6 animals was used as control without receiving further treatment. Four groups of 6 to 8 animals each then received a PN graft immediately, or 1, 2, or 3 weeks later.

In animals destined to receive $\mathrm{PN}$ grafts, the spinal motoneurons at $\mathrm{C} 7$ were prelabeled with fast blue (FB) 2 days before the root avulsion was carried out. After avulsion, a piece of femoral nerve (PN graft), about $2 \mathrm{~cm}$ long, was implanted into the lesioned spinal segment by suturing its central end with 11-0 suture into a small cut on the surface of the lateral funiculus at C7. The peripheral end of the graft was implanted into skeletal muscle adjacent to the vertebral column. The total survival time for all animals was 6 weeks after root avulsion. Two days before the end of the survival period, animals were reanesthetized, and the implanted grafts were identified and labeled with a second dye, diamidino yellow (DY). The tracers FB and DY can be differentiated within neurons by their distinct colors and localizations within different subcellular compartments in the cell body (FB is distributed within the cytoplasm, whereas DY is concentrated in the nucleus). Based on the experimental design, the FB-labeled neurons represent surviving motoneurons that did not regenerate into the PN graft following avulsion. FB and DY double-labeled neurons represent surviving motoneurons that regenerated into the PN graft following avulsion.

\section{Perfusion and Tissue Processing}

At the end of the survival period, the rats were given a lethal dose of Nembutal. The thoracic cavity was opened and perfused intracardially with phosphatebuffered saline (PBS). Then the animals were perfused with $200-300 \mathrm{~mL}$ of fixative containing $4 \%$ paraformaldehyde and $0.2 \%$ picric acid in $0.1 \mathrm{M}$ PBS $(\mathrm{pH}$ 7.4). After perfusion, the implanted PN graft was carefully examined under an operating microscope. Only specimens with clearly successful implants, showing a tight connection between the graft and the host spinal cord, were used for data analysis. The lesioned segments of the spinal cord were removed and immersion-fixed in fresh fixative for $4-6 \mathrm{~h}$ and then placed in $30 \%$ phosphate-buffered sucrose overnight.

On the following day, $30-\mu \mathrm{m}$ frozen sections were cut, collected in 0.1 M PBS, and mounted onto glass slides for fluorescent microscopy.

\section{NADPH Diaphorase Histochemistry}

Expression of nNOS was detected by NADPH diaphorase histochemistry (NADPH-d). Sections were in- 
cubated at $37^{\circ} \mathrm{C}$ for $1 \mathrm{~h}$ in $10 \mathrm{~mL}$ of $0.1 \mathrm{M}$ Tris-HCL (pH 8.0) containing $10 \mathrm{mg}$ of NADPH (Sigma) and $2.5 \mathrm{mg}$ of nitro blue tetrazolium, and then counterstained with neutral red. This method has previously been proven to identify nNOS-containing neurons under normal conditions (Bredt et al., 1991; Dawson et al., 1991; Hope et al., 1991; Vincent et al., 1992). We have also previously demonstrated that NADPH-d stains exactly the same population of lesioned motoneurons visualized by nNOS-immunocytochemistry and nNOS in situ hybridization $(\mathrm{Wu}$ et al., 1994b).

\section{Immunocytochemistry Staining for p75}

Procedures for immunocytochemistry (ICC) staining were similar to those used in a previous study ( $\mathrm{Wu}$, 1996). Briefly, sections were incubated in primary antibody to 75 (Oncogene Science, Inc. Cambridge, MA) for $48 \mathrm{~h}$ at $4^{\circ} \mathrm{C}$. The antibody was applied in 1:1000 dilution in $0.1 \mathrm{M}$ PBS containing $2 \%$ normal serum and $0.2 \%$ Triton X 100. Then, sections were washed in PBS three times for $10 \mathrm{~min}$ each, and incubated in biotinylated secondary antiserum (Vectastain ABC kit, Vector Lab, Burlingame, CA) for $40 \mathrm{~min}$ at room temperature. Sections were rinsed and incubated in $\mathrm{ABC}$ reagents (Vectastain ABC kit) for 60 min. Sections were then washed thoroughly and incubated in $0.05 \% \mathrm{DAB}$ and $0.03 \% \mathrm{H}_{2} \mathrm{O}_{2}$ for $3-5$ min until a brown reaction product was observed.

\section{Double Staining of ICC and NADPH-d}

After ICC staining, sections were processed further for NOS staining with NADPH-d histochemistry as described above. Both the brown ICC product (p75) and the blue NADPH-d product (NOS) were present on the same sections, and they were easily identifiable.

\section{Retrograde Injury-Filling of Regenerated Spinal Motoneurons with Fluorescent Dyes}

Prelabeling was performed under anesthesia 2 days before the root avulsion. One to $2 \mu \mathrm{L}$ of $2 \%$ fast blue (FB) solution (Sigma) was injected into the C7 spinal nerve. The nerve was then crushed at the injection site with a no. 5 forceps for $5 \mathrm{sec}$ to ensure all axons were injured. Two days after FB injection, animals underwent root avulsion and graft implantation as described above. Two days before the end of the survival period, animals were reanesthetized, the implanted grafts were identified, and the second dye, DY $(2 \%$, $1-2 \mu \mathrm{L}$ ), was injected into the grafts $10 \mathrm{~mm}$ distal to the spinal cord following the procedure described above.

\section{Motoneuron Counts}

Motoneurons in the C7 spinal cord were counted blindly on both sides of the spinal cord in all sections that were stained with NADPH-d and counterstained with neutral red, as described previously ( $\mathrm{Wu}, 1993)$. The number of motoneurons on the contralateral (intact) side served as the normal control and was expressed as $100 \%$. The numbers of motoneurons were compared among groups. Data were analyzed with a one-way analysis of variance (ANOVA) followed by Tukey-Kramer multiple comparison tests.

\section{RESULTS}

\section{Survival of Motoneurons in Avulsed Spinal Segment after Delayed PN Graft Implantation}

The PN grafts from most animals with immediate or delayed implantation were tightly connected with the host spinal cord. Implanted grafts looked normal and similar to the adjacent spinal roots (Fig. 1). One or two samples from each group did not show a good connection to the host and were not used. In general, the earlier the PN graft was implanted, the higher the percentage of motoneuron survival. In the control animals, which did not receive a PN graft, about $30 \pm 4.9 \%$ of motoneurons survived in the injured segment at 6 weeks after avulsion as compared with the intact, contralateral side. PN graft implantation immediately after root avulsion significantly increased motoneuron survival to $78 \pm 7.5 \%$ after the same postinjury time. The motoneuron survival rate then decreased to $65 \pm 6.8 \%, 57 \pm 6.9 \%$, or $53 \pm 7.9 \%$ as implantation was delayed 1, 2, or 3 weeks after root avulsion, respectively (Fig. 2), but all of the survival rates were higher than that of the control. In addition, the survival rate of motoneurons in the immediately implanted group was significantly higher than that of all delayed implanted groups. Differences among the delayed implanted groups were not statistically significant (Fig. 2).

\section{Regeneration of Injured Motoneurons into the Delayed Implant}

Although the number of surviving motoneurons was affected by the timing of PN graft implantation, most surviving motoneurons were able to regenerate their axons into the PN graft regardless of the time of implantation. The rate of regeneration in the different groups was similar. Eighty-five percent of the surviving motoneurons regenerated when the PN graft was implanted immediately after root avulsion. Although the total number of surviving motoneurons decreased in the groups with delayed PN graft implantation, $84 \%, 82 \%$, and $83 \%$ of them were 


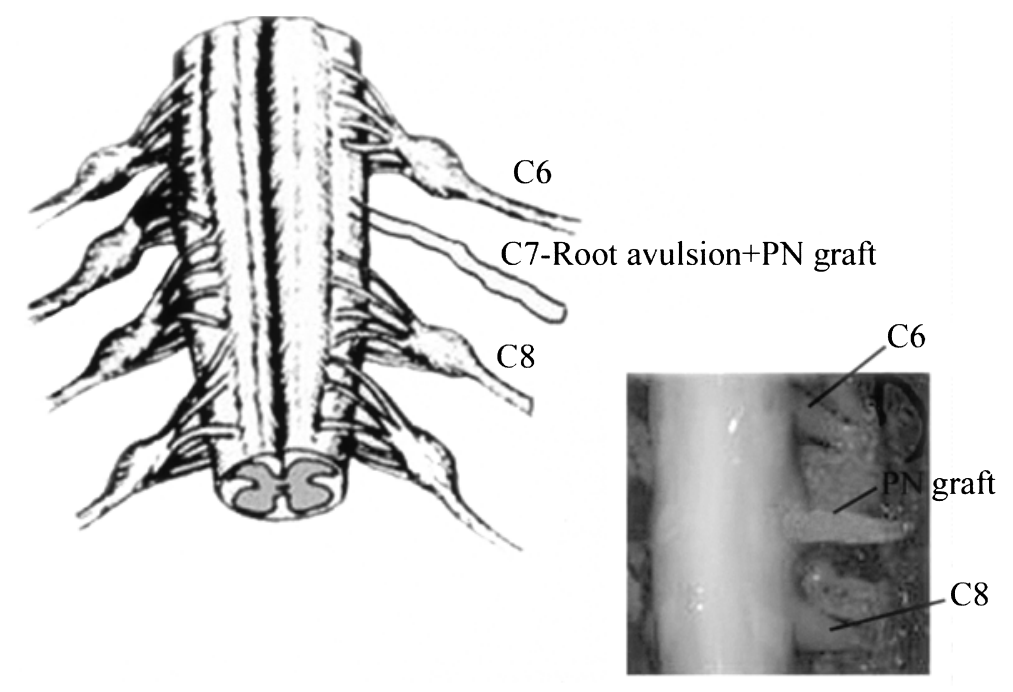

FIG. 1. Diagrams illustrating PN graft implantation after root avulsion. The C7 spinal roots, both ventral and dorsal, together with the dorsal root ganglion were avulsed and a PN graft was implanted into the lesioned side. The inset shows the PN graft was satisfactorily connected to the lesioned area as shown under an operating microscope after perfusion fixation.

found to have regenerated into the delayed PN grafts at 1, 2, or 3 weeks postinjury, respectively (Fig. 2).

\section{Expression Patterns of NOS and p75 in Injured Motoneurons after Delayed Implantation}

Expression of NOS in spinal motoneurons after root avulsion was dramatically downregulated in all animals with a PN graft regardless of the time of implantation (Fig. 3C). Even in those animals receiving a graft 3 weeks postavulsion, when more than $80 \%$ of injured motoneu- rons have expressed NOS in controls, expression of the enzyme was significantly downregulated after PN implantation. Furthermore, all regenerated motoneurons also expressed p75 (Fig. 3A-C). In contrast, all the motoneurons that failed to regenerate expressed NOS but not $\mathrm{p} 75$, regardless of the postavulsion time of PN graft implantation and the number of motoneurons regenerated (Fig. 3A-C). For example, in one case of a delayed and poorly implanted graft, only one motoneuron regenerated an axon into the graft, and that motoneuron expressed p75 while the remainder expressed NOS (Fig. 3D-F).

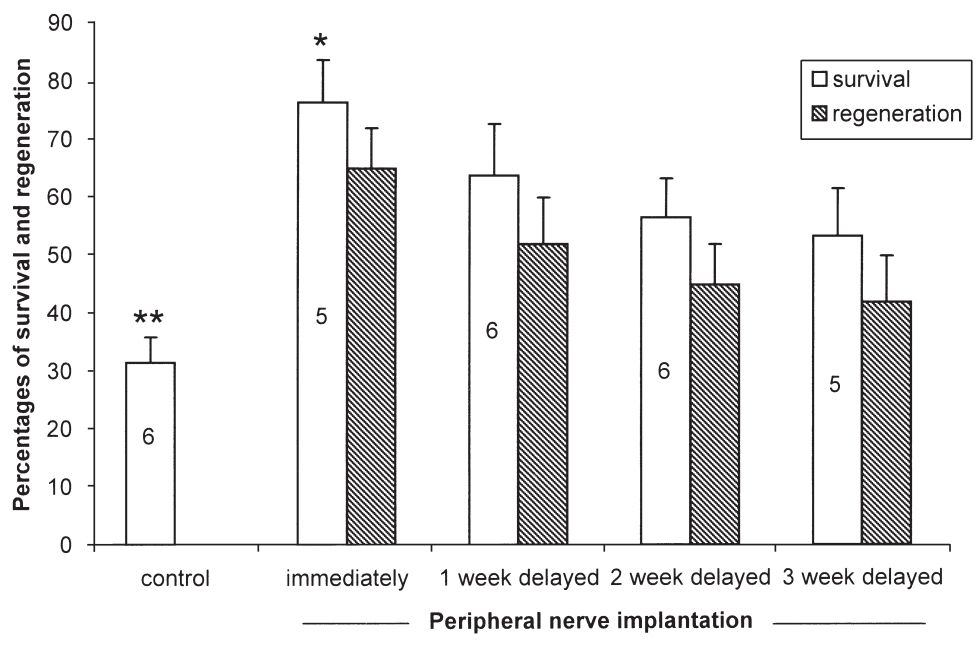

FIG. 2. Survival and regeneration of avulsed spinal motoneurons following delayed PN implantation. The numbers of motoneurons that survived and were regenerated are expressed as mean percentage \pm SD. Numbers in bars represent numbers of animal examined in each group. ${ }^{* *} p<0.001$ versus all other groups. ${ }^{*} p<0.05,0.01,0.001$ versus 1 week, 2 week, and 3 week delayed, respectively. 

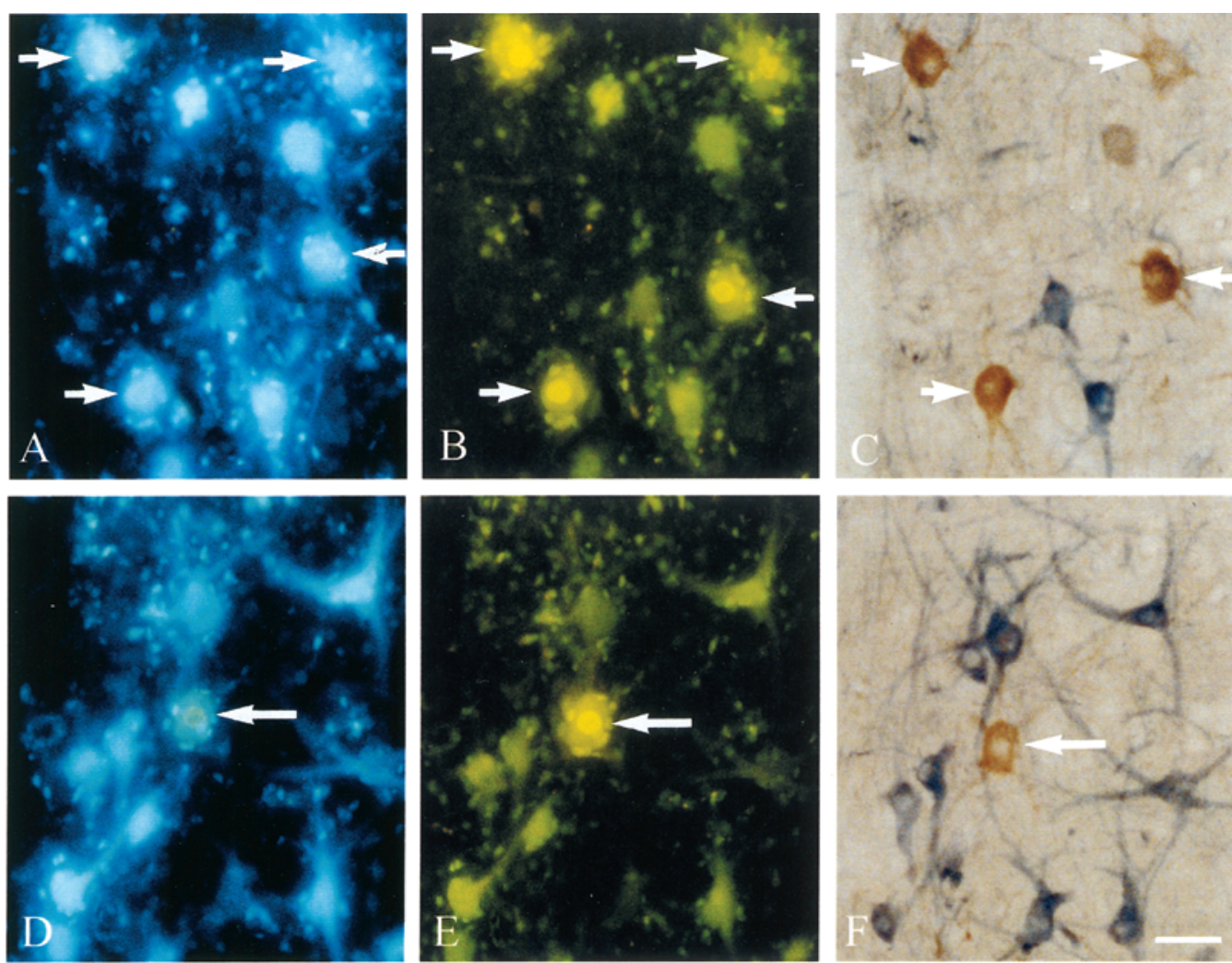

FIG. 3. Horizontal sections through the ventral horns of the spinal cords. (A-C) from a rat that underwent a successful implantation of a PN graft 2 weeks after root avulsion. (D-F) From a rat that also underwent implantation of a PN graft 2 weeks after root avulsion, but the PN graft was poorly connected with the host. Motoneurons were prelabeled with FB 2 days before root avulsion. A PN graft was then implanted 2 weeks after root avulsion. Four weeks after implantation, DY was applied into the graft and animals were perfused and prepared for fluorescent microscopy, then sections were immunocytochemically stained for p75 and NOS histochemistry. In successful implantation, many motoneurons were found to regenerate their axons into the PN graft (arrows in A and B, FB and DY double labeled). The regenerated motoneurons expressed p75 (arrows in C) and the nonregenerated ones (labeled by FB but not DY) expressed NOS (blue cells in C). In poor implantation, only one motoneuron was found to regenerate its axon into the PN graft (arrow in D and E, FB and DY double labeled). It was this motoneuron that expressed p75 (arrow in F). The rest of the motoneurons, which were NOS positive, were unable to regenerate their axons into the PN graft (blue cells in F). Bar $=50 \mu \mathrm{m}$.

\section{DISCUSSION}

\section{Survival of Spinal Motoneurons following Axonal Injury}

It is well known that transection of motoneuron axons or removal of their targets during embryonic or early postnatal development results in massive motoneuron loss, whereas axotomy of adult PN induces little if any neuronal death (Kashihara et al., 1987; Pollin et al., 1991; Schmalbruch, 1988; Lowrie et al., 1992). However, severe axonal injury, as in spinal root avulsion, can cause a massive motoneuron loss in adult animals (Wu, 1993, 1996; Koliatsos et al., 1994; Novikov et al., 1995). Recently, the root avulsion model has been widely used to study mechanisms underlying neuronal death and regen- eration following axonal injury (Cullheim et al., 1999; Martin et al., 1999; He et al., 2000; Hammarberg et al., 2000; Chan et al., 2001; Yamada et al., 2001).

Several experimental manipulations have been reported to prevent motoneuron death in adult animals suffering root avulsion. Among these manipulations, implantation of a PN graft (Wu et al., 1994a, Holtzer et al., 1996; Liu et al., 1998; Chai et al., 2000; Kassar-Duchossy et al., 2001; Rhrich-Haddout et al., 2001) or treatment with neurotrophic factors (Wu et al., 1995, Novikov et al., 1995; Oorschot et al., 1998; Watabe et al., 2001) greatly enhanced survival. In those studies, the segment of nerve was usually implanted immediately following root avulsion. In the present study, we have shown that delayed implantation can still rescue the remaining 
motoneurons from degeneration. It seems that adult motoneurons retain the ability to survive following root avulsion. This ability remains only for a short period, after which most of the injured motoneurons die. Within this limited period of time, motoneurons can be rescued by providing a suitable environment, such as a PN graft. The proportion of motoneurons rescued depends on the number surviving at the time of implantation. In general, the earlier the PN graft is implanted, the greater the number of injured motoneurons that can survive. PN graft implantation immediately after root avulsion has the most favorable effect on motoneuron survival. The difference in the survival rate between the immediate-implantation group and the 1 week-delayed group is smaller than that between other prolonged delayed groups. Therefore, the best time for the PN graft implantation seems to be within 1 week after root avulsion.

\section{Regenerating Capacity of Spinal Motoneurons following Axonal Injury}

Although it is well established that many types of CNS neurons can regrow their axons into a PN graft following injury (Aguayo et al., 1982), the capacity for such axonal sprouting varies among populations of neurons. Factors that affect axonal regrowth include the type of neurons under investigation, their age, and the time of PN transplantation after injury. In adult animals, for example, corticospinal neurons are unable to regrow their axons into a PN graft following axotomy (Decherchi et al., 2000), whereas spinal motoneurons are capable of regenerating their axons into a PN graft (Wu et al., 1994a). This illustrates differences in the intrinsic capacity for axonal regrowth between these two types of neurons.

One important finding of the present study is that the majority of injured motoneurons were able to regenerate their axons into the graft after a delay. Both the total number of regenerating motoneurons and the total number of motoneurons surviving was greater in animals that underwent earlier implantation than in those implanted later. The rate of successful regeneration in the avulsed motoneurons, however, was about the same (about $80 \%$ of surviving motoneurons) regardless of the length of time that passed between the injury and implantation. This finding indicates that avulsed motoneurons can regenerate if a permissive environment is provided. Therefore, it may never be too late to implant a PN graft after root avulsion as long as surviving motoneurons remain.

\section{Potential Roles of nNOS and p75 in Motoneuron Survival and Regeneration}

Our previous study showed that expression of nNOS in damaged motoneurons could be prevented if a PN graft is implanted immediately after root avulsion (Wu et al., 1994a; Wu, 1996). A potential mechanism underlying this phenomenon may be that injured motoneurons obtain trophic support from the PN graft before the expression of nNOS is turned on. In the present study, we have shown that PN graft implantation several weeks after root avulsion can still inhibit the expression of nNOS even after the expression of nNOS has been initiated and this enzyme has reached its maximum level in the injured motoneurons. Such inhibition of nNOS expression was observed in regenerating motoneurons but not in those that failed to regenerate, suggesting that factors from the graft are responsible for the inhibition of nNOS expression, and that nNOS may not be required for motoneuron regeneration.

The mechanism underlying the expression of nNOS in adult spinal motoneurons following root avulsion remains unknown. nNOS seems to play different roles in different populations of neurons. Previous studies have demonstrated that expression of nNOS in spinal motoneurons seems to be associated with the degenerative process $(\mathrm{Wu}$, 1993; Wu et al., 1994b) and is a cytotoxicity marker for the injured motoneurons (He et al., 2003). In cerebellar Purkinje cells, NOS expression is also coincident with the death of injured cells (Chen et al., 1993). On the other hand, a study of axonal injury in cranial motoneurons suggests that NOS expression is not related to the death of injured neurons but is correlated with axonal regeneration (Yu, 2002). In the hypothalamus, increased expression of NOS is also associated with regeneration processes in magnocellular neurons of the supraoptic and paraventricular nuclei following hypophysectomy (Wu and Scott, 1993).

Although the precise relationship between the expression of nNOS and neuronal injury is unclear, nNOS expression in injured motoneurons may act via one of the following mechanisms. First, NOS/NO may be neurotoxic and directly responsible for the death of injured motoneurons. Second, NOS/NO might act as a replacement for neurotrophic factors when motoneurons are deprived of them. This may explain why nNOS is induced in motoneurons injured by root avulsion but not by distal axotomy (Wu, 1993; Gu et al., 1997). In distal axotomy, motoneurons may still obtain trophic factors from the remaining peripheral environment, which in turn may prevent the expression of nNOS, whereas in root avulsion, motoneurons lose the peripheral source of trophic support, and so the expression of nNOS is induced. Inhibition of nNOS expression in regenerated motoneurons following PN graft implantation seems to support this hypothesis since regenerated motoneurons that are able to obtain neurotrophic support from the PN graft no longer need NOS/NO. Further study is needed to elucidate the precise role of nNOS in injured motoneurons. 
The role and expression of p75 in embryonic and early postnatal spinal motoneurons have been thoroughly investigated, but p75 is not expressed in mature spinal motoneurons (Bothwell, 1995; Chiu et al., 1993; Ernfors et al., 1989). Adult motoneurons re-express p75 after axonal injury such as sciatic nerve crush (Chiu et al., 1993; Ernfors et al., 1989). Although the precise role of such expression is not clear, re-expression of p75 in injured motoneurons coincides with their survival and regeneration (Wu, 1996). The results of the present study provide further support to the idea that p75 plays a beneficial role in neuronal recovery from axonal injury. First, p75 can inhibit cell death induced by traumatic injury and by neurotoxic beta-amyloid peptide, and promote neurite outgrowth, axonal extension, and neuronal survival by binding neurotrophins such as CNTF, BDNF, NGF, or monoclonal antibody (Rabizadeh et al., 1993, 1994). Second, re-expression of p75 is observed only in motoneurons that are sprouting, so the signals that trigger and sustain this re-expression may originate in the periphery (Rende et al., 1993). The re-expression of p75 in regenerated motoneurons after delayed implantation of a PN graft found in the present study may simply reflect the retrograde transport of neurotrophic factors from the PN graft. Third, p75 is expressed not only in axons but also in the pathways along which they grow, including Schwann cells, which could present neurotrophins to growing axons (Lee et al., 1994). In conclusion, re-expression of p75 appears to play a beneficial role in neuronal survival and regeneration following axonal injury.

A further interesting finding of the present study is that, without exception, all regenerating motoneurons express $\mathrm{p} 75$, whereas all motoneurons that fail to regenerate express nNOS, regardless of the time of graft implantation or the number of motoneurons that actually send axons into the graft. Therefore, the expression of p75 can be used as a marker for the successful regeneration of spinal motoneurons, and expression of nNOS can serve as a marker for unsuccessful regeneration.

\section{ACKNOWLEDGMENTS}

This study was supported by grants from the University of Hong Kong Research Grant Council (Project No. HKU7381/00M). We are grateful to Dr Iain Bruce of the Department of Physiology at HKU for helpful comments on the manuscript.

\section{REFERENCES}

AGUAYO, A.J., DAVID, S., RICHARDSON, P., et al. (1982). Axonal elongation in peripheral and central nervous system transplants, in: Advances in Cellular Neurobiology. S. Fedoroff and L. Hertz (eds), Academic Press: New York, pps. 215-234.

BOTHWELL, M. (1995). Functional interactions of neurotrophins and neurotrophin receptors. Annu. Rev. Neurosci. $18,223-253$.

BREDT, D.S., GLATT, C.E., HWANG, P.M., et al. (1991). Nitric oxide synthase protein and mRNA are discretely localized in neuronal populations of the mammalian CNS together with NADPH diaphorase. Neuron 7, 615-624.

CHAI, H., WU, W., SO, K.F., et al. (2000). Survival and regeneration of motoneurons in adult rats by re-implantation of ventral root following spinal root avulsion. NeuroReport $11,1249-1252$.

CHAN, Y.M., WU, W., YIP, H., et al. (2001). Caspase inhibitors promote the survival of avulsed spinal motoneurons in neonatal rats. NeuroReport 12, 541-545.

CHEN, S., and ASTON-JONES, G. (1993). Possible induction of nitric oxide synthase in Purkinje neurons following injury. Soc. Neurosci. Abst. 19, 1876.

CHIU, A.Y., CHEN, E.W., and LOERA, S. (1993). A motoneuron-specific epitope and the low-affinity nerve growth factor receptor display reciprocal patterns of expression during development, axotomy, and regeneration, J. Comp. Neurol. 328, 351-363.

CULLHEIM, S., CARLSTEDT, T., and RISLING, M. (1999). Axon regeneration of spinal motoneurons following a lesion at the cord-ventral root interface. Spinal Cord 37, 811-819.

DAWSON, T.M., BREDT, D.S., FOTUHI, M., et al. (1991). Nitric oxide synthase and neuronal NADPH-diaphorase are identical in brain and peripheral tissues. Proc. Natl. Acad. Sci. U.S.A. 88, 7797-7801.

DECHERCHI, P., and GAUTHIER, P. (2000). Regrowth of acute and chronic injured spinal pathways within supra-lesional post-traumatic nerve grafts. Neuroscience 101, 197-210.

ERNFORS, P., HENSCHEN, A., OLSON, L., et al. (1989). Expression of nerve growth factor receptor mRNA is developmentally regulated and increased after axotomy in rat spinal cord motoneurons. Neuron 2, 1605-1613.

GU, YM, SPASIC, Z., and WU, W. (1997). The effects of remaining axons on motoneuron survival and NOS expression following axotomy in the adult rat. Dev. Neurosci. 19, 255-259.

HAMMARBERG, H., PIEHL, F., RISLING, M., et al. (2000). Differential regulation of trophic factor receptor mRNAs in spinal motoneurons after sciatic nerve transection and ventral root avulsion in the rat. J. Comp. Neurol. 426, 587-601.

HE, J.W., HIRATA, K., KURAOKA, A., et al. (2000). An improved method for avulsion of lumbar nerve roots as an experimental model of nitric oxide-mediated neuronal 
degeneration. Brain Res. Brain Res. Protoc. 5, 223 230 .

HE, J.W., HIRATA, K., WANG, S., et al. (2003). Expression of nitric oxide synthase and $27-\mathrm{kD}$ heat shock protein in motor neurons of ventral root-avulsed rats. Arch. Histol. Cytol. 66, 83-93.

HOLTZER, C.A., DAHAN, A., VERSCHURE, P.C., et al. (1996). Nerve grafting from spinal cord to spinal nerve: a microsurgical technique in cats. J. Neurosci. Methods. 70, $163-169$.

HOPE, B.T., MICHAEL, G.J., KNIGGE, K.M., et al. (1991). Neuronal NADPH-diaphorase is a nitric oxide synthase. Proc. Natl. Acad. Sci. U.S.A. 88, 2811-2814.

KASHIHARA, Y., KUNO, M., and MIYATA, Y. (1987). Cell death of axotomized motoneurons in neonatal rats, and its prevention by peripheral reinnervation. J. Physiol. (Lond.) 386, 135-148.

KASSAR-DUCHOSSOY, L., DUCHOSSOY, Y., RHRICHHADDOUT, F., et al. (2001). Reinnervation of a denervated skeletal muscle by spinal axons regenerating through a collagen channel directly implanted into the rat spinal cord. Brain Res. 908, 25-34.

KOLIATSOS, V.E., PRICE, W.L., PARDO, C.A., et al. (1994). Ventral root avulsion: an experimental model of death of adult motor neurons. J. Comp. Neurol. 342, 35-44.

LEE, K.F., BACHMAN, K., LANDIS, S., et al. (1994). Dependence on $\mathrm{p} 75$ for innervation of some sympathetic targets. Science. 263, 1447-1449.

LIU, S., BODJARIAN, N., LANGLOIS, O., et al. (1998). Axonal regrowth through a collagen guidance channel bridging spinal cord to the avulsed C6 roots: functional recovery in primates with brachial plexus injury. J. Neurosci. Res. 51, 723-734.

LOWRIE, M.B., and VRBOVA, G. (1992). Dependence of postnatal motoneurons on their targets: review and hypothesis. Trends Neurosci. 15, 80-84.

MARTIN, L.J., KAISER, A., and PRICE, A.C. (1999). Motor neuron degeneration after sciatic nerve avulsion in adult rat evolves with oxidative stress and is apoptosis. J. Neurobiol. 40, 185-201.

NOVIKOV, L., NOVIKOVA, L., and KELLERTH, J.O. (1995). Brain-derived neurotrophic factor promotes survival and blocks nitric oxide synthase expression in adult rat spinal motoneurons after ventral root avulsion. Neurosci. Lett. 200, $45-48$.

OORSCHOT, D.E., and McLENNAN, I.S. (1998). The trophic requirements of mature motoneurons. Brain Res. 789, $315-321$.

POLLIN, M.M., McHANWELL, S., and SLATER, C.R. (1991). The effect of age on motor neurone death following axotomy in the mouse. Development 112, 83-89.
RABIZADEH, S., OH, J., ZHONG, L.T., et al. (1993). Induction of apoptosis by low-affinity NGF receptor. Science $\mathbf{2 6 1}$, 345-348.

RABIZADEH, S., BITLER, C.M., BUTCHER, L.L., et al. (1994). Expression of the low-affinity nerve growth factor receptor enhance beta-amyloid peptide toxicity. Proc. Natl. Acad. Sci. USA 91, 10703-10706.

RENDE, M., PROVENZANO, C., and TONALI, P. (1993). Modulation of low-affinity nerve growth factor receptor in injured adult rat spinal cord motoneurons. J. Comp. Neurol. 338, 560-574.

RHRICH-HADDOUT, F., KASSAR-DUCHOSSOY, L., BAU-CHET, L., et al. (2001). Alpha-motoneurons of the injured cervical spinal cord of the adult rat can reinnervate the biceps brachii muscle by regenerating axons through peripheral nerve bridges: combined ultrastructural and retrograde axonal tracing study. J. Neurosci. Res. 64, 476-486.

SCHMALBRUCH, H. (1988). The effect of peripheral nerve injury on immature motor and sensory neurons and on muscle fibers. Rev. Neurol. (Paris) 144, 721-729.

VINCENT, S.R., and KIMURA, H. (1992). Histochemical mapping of nitric oxide synthase in the rat brain. Neuroscience 46, 755-784.

WATABE, K., SAKAMOTO, T., OHASHI, T., et al. (2001). Adenoviral gene transfer of glial cell line-derived neurotrophic factor to injured adult motoneurons. Hum. Cell 14, $7-15$.

WU, W. (1993). Expression of nitric oxide synthase (NOS) in injured CNS neurons as shown by NADPH-diaphorase histochemistry. Exp. Neurol. 120, 153-159.

WU, W., and SCOTT, D.E. (1993). Increased expression of nitric oxide synthase in hypothalamic neuronal regeneration. Exp. Neurol. 121, 279-283.

WU, W., HAN, K., LI, L., et al. (1994a). Implantation of PNS graft inhibits the induction of neuronal nitric oxide synthase and enhances the survival of spinal motoneurons following root avulsion. Exp. Neurol. 129, 335-339.

WU, W., LIUZZI, F.J., SCHINCO, F.P., et al. (1994b). Neuronal nitric oxide synthase is induced in spinal neurons by traumatic injury. Neuroscience 61, 719-726.

WU, W., LI, L., PENIX, J.O., et al. (1995). GDNF and BDNF inhibite the induction of NOS and prevent the death of adult rat spinal motoneurons following root avulsion. Neurosci. Abst. 21, 279.

WU, W. (1996). Potential roles of gene expression changes in adult rat spinal motoneurons following axonal injury: a comparison among c-jun, low affinity nerve growth factor receptor (LNGFR), and nitric oxide synthase (NOS). Exp. Neurol. 141, 190-200. 
YAMADA, M., NATSUME, A., MATA, M., et al. (2001). Herpes simplex virus vector-mediated expression of Bcl-2 protects spinal motor neurons from degeneration following root avulsion. Exp. Neurol. 168, 225-230.

YU, W.H.A. (2002). Spatial and temporal correlation of nitric oxide synthase expression with $\mathrm{CuZn}$-superoxide dismutase reduction in motor neurons following axotomy. Ann. N.Y. Acad. Sci. 962, 111-121.
Address reprint requests to: Wu-Tian Wu, M.D., Ph.D.

Department of Anatomy Faculty of Medicine

The University of Hong Kong 21 Sassoon Road Hong Kong, China

E-mail:wtwu@hkucc.hku.hk 